Pacific Journal of Mathematics

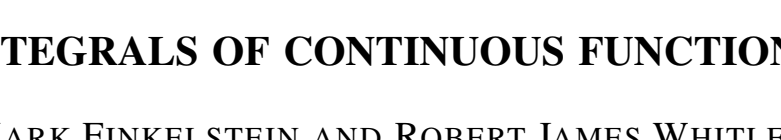




\section{INTEGRALS OF CONTINUOUS FUNCTIONS}

\section{MARK Finkelstein AND ROBERT Whitley}

Semicontinuous and related functions are characterized as integrals of continuous functions in several variables. For example: a new result of classical type is that the nonnegative lower semicontinuous functions on the real line are exactly those functions $f$ which can be written as

$$
f(s)=\int_{-\infty}^{\infty} h(s, t) d t,
$$

with $h$ nonnegative and continuous on $R \times R$ and $h(s, \cdot)$ integrable. There is a similar representation for functions of Baire class 0 or 1 but the integral involved is the (conditional) improper Riemann integral. Generalization leads to a concept of conditional integrals in a more general setting.

We will consider a locally compact but not compact metric space $S$. All functions on $S$ will be real valued, not extended real valued. Recall that $[1,2,5,6]$ : a function $f$ is lower semicontinuous iff $f^{-1}(a, \infty)$ is open for each $a$, and a function $f$ is l.s.c. iff there is a monotone increasing sequence of continuous functions converging pointwise to $f$.

THEOREM 1. A nonnegative function $f$ on $S$ is lower semicontinuous iff there is a nonnegative function $h$, continuous on $S \times R$, with $h(s, \cdot)$ integrable for each $s$, and

$$
f(s)=\int_{-\infty}^{\infty} h(s, x) d x
$$

Proof. Suppose that (1) holds as described. The function

$$
f_{n}(s)=\int_{-n}^{n} h(s, x) d x
$$

is continuous. The sequence $\left\{f_{n}\right\}$ converges monotonically to $f$ which is therefore l.s.c.

Conversely, suppose that $f$ is l.s.c. and let $\left\{f_{n}\right\}$, with $f_{1}=0$, be a sequence of continuous functions increasing pointwise to $f$. By truncating each function $f_{n}$ at $\pm n$ (redefine $f_{n}$ to be $n$ when $f_{n}(s)>n$ and redefine $f_{n}$ to be $-n$ when $\left.f_{n}(s)<-n\right)$ we have $\left|f_{n}\right| \leqq n$. There is obviously a sequence of continuous functions $h_{n}$ on $R$ satisfying $0 \leqq h_{n} \leqq 1 /(2 n+1) 2^{n}$ and $\int_{-\infty}^{\infty} h_{n}(x) d x=1$. Consider 


$$
h(s, x)=\sum_{n=1}^{\infty}\left(f_{n+1}(s)-f_{n}(s)\right) h_{n}(x) .
$$

This nonnegative function is continuous on $S \times R$ because of the uniform convergence of the series. Integrate both sides of (2) and apply the monotone convergence theorem to obtain equation (1).

Theorem 1 directly gives a representation for an arbitrary lower semicontinuous function $f$; just choose $g$ continuous with $g \leqq f$, then $f(s)=g(s)+\int h(s, x) d x$. Conversely any $f$ which can be so written is lower semicontinuous.

There is an historical context into which Theorem 1 fits nicely:

From Theorem 1 the problem which Young [4, pg. 151] solved of defining a new type of integral for $\bar{f}$ and $f$ is exactly equivalent to defining $\int_{a}^{b} \int_{-\infty}^{\infty} h(x, y) d y d x$ for a nonnegative continuous bounded function $h$ on $[a, b] \times R$. This is an interesting relation between iterating (improper) integrals and extending the class of functions over which a single integral is defined.

A function $f$ belongs to the Baire class zero if it is continuous, to Baire class one if it is discontinuous but is the pointwise limit of a sequence $\left\{f_{n}\right\}$ of continuous functions [1, 3, 6], Hausdorff, [3, $\S 41]$, has discussed a special subclass of Baire class $\leqq 1$, those functions of "type $d$ ", which are exactly those having the property that they can be written as the series

$$
f(x)=\sum_{n=1}^{\infty} f_{n+1}(x)-f_{n}(x)
$$

with the series being absolutely convergent. In this case the series $\sum\left(f_{n+1}(x)-f_{n}(x)\right)^{+},\left(a^{+}=\max (a, 0)\right)$, converges monotonically to a function $g$ which is therefore lower semicontinuous, and the series $\sum\left(f_{n+1}(x)-f_{n}(x)\right)^{-},\left(\alpha^{-}=-\min (\alpha, 0)\right)$, likewise converges to a l.s.c. function $h$. Thus $f=g-h$ is the difference of two l.s.c. functions and, conversely, any function which can be so written as the difference of two l.s.c. functions is of type $d$.

Using these elementary facts and Theorem 1, any function $f$ of type $d$ can be represented as the integral $\int h(s, x) d x, h$ a continuous function on $S \times R$ with $h(s, \cdot)$ integrable. Conversely, any $f$ which can be so written as an integral can be written as $\int h(s, x)^{+} d x-$ $\int h(s, x)^{-} d x$ and so is of type $d$. Note that if $f$ is of type $d$ then the series (2) can be integrated term by term by the dominated convergence theorem.

We now want to represent the functions of Baire class one in 
the form (1), but in order to get the entire class, and not just those of type $d$, the integral involved must be a conditionally convergent integral.

THEOREM 2. A function $f$ belongs to Baire class 0 or 1 iff there is a function $h$, continuous on $S \times R$, with $h(s, \cdot)$ improperly Riemann integrable on $R$, and

$$
f(s)=\int_{-\infty}^{\infty} h(s, x) d x .
$$

Proof. If $f$ can be represented by (3), then $f(s)=\lim \int_{-n}^{n} h(s, x) d x$ and $f$ belongs to either Baire class 0 or Baire class 1 .

Conversely, suppose that $f$ belongs to Baire class 0 or $1 ; f(s)=$ $\lim f_{n}(s)$, the pointwise limit of a sequence of continuous functions. We can take $f_{1}=0$.

As in Theorem 1 , by truncating the functions $f_{n}$ we may suppose that $\left|f_{n}\right| \leqq n$. At this point in the proof we need to use more finesse than in Theorem 1 in choosing the functions $\left\{h_{n}\right\}$. Let $h_{n}(x)=0$ for $|x| \geqq(2 n+1) 2^{n}, h_{n}(0)=1 /(2 n+1) 2^{n}$, and $h_{n}$ linear otherwise. The important properties that these continuous functions have are: $0 \leqq h_{n} \leqq 1 /(2 n+1) 2^{n}, \int_{-\infty}^{\infty} h_{n}(x)=1$, and for any $a<0<b, \int_{a}^{b} h_{n}(x) d x$ converges monotonically to zero as $n$ tends to infinity.

As in Theorem 1 , define $h(s, x)=\sum_{n=1}^{\infty}\left(f_{n+1}(s)-f_{n}(s)\right) h_{n}(x)$, a continuous function on $S \times R$. For $a<0<b$, apply the bounded convergence theorem to obtain

$$
\int_{a}^{b} h(s, x) d x=\sum_{n=1}^{\infty}\left(f_{n+1}(s)-f_{n}(s)\right) \int_{a}^{b} h_{n}(x) d x .
$$

Let $\varepsilon>0$ be given. As $\sum\left(f_{n+1}(s)-f_{n}(s)\right)=f(s)$, there is an $N$ (which may depend on $s$ ) with $\left|\sum_{n=k}^{\infty} f_{n+1}(s)-f_{n}(s)\right| \leqq \varepsilon$ for $k \geqq N$. Let $a_{n}=f_{n+1}(s)-f_{n}(s), b_{n}=\int_{a}^{b} h_{n}(x) d x$, and $A_{N+k}=\sum_{j=N+1}^{N+k} a_{j}$. To estimate $\sum_{N+1}^{N+p} a_{n} b_{n}$ use Abel's formula for summation by parts [6, II, $\S 24]: \sum_{N+1}^{N+p} a_{n} b_{n}=A_{N+p} b_{N+p+1}-\sum_{N+1}^{N+p} A_{n}\left(b_{n+1}-b_{n}\right)$. Since $\left\{b_{n}\right\}$ converges to zero monotonically, $\left|\sum_{N+1}^{N+p} a_{n} b_{n}\right| \leqq \sup _{k \geqq N}\left|A_{k}\right| b_{N+1} \leqq \varepsilon$. Let $a \rightarrow-\infty$ and $b \rightarrow \infty$. Then $\int_{a}^{b} h_{n}(x) d x \rightarrow 1$ and thus $\sum_{1}^{N}\left(f_{n+1}(s)-\right.$ $\left.f_{n}(s)\right) \int_{a}^{b} h_{n}(x) d x \rightarrow \sum_{1}^{N} f_{n+1}(s)-f_{n}(s)$ which is within $\varepsilon$ of $f(s)$. It follows that

$$
\lim _{\substack{a \rightarrow-\infty \\ b \rightarrow \infty}} \int_{a}^{b} h(s, x) d x=f(s)
$$

THEOREM 3. A function $f$ on $S$ is of Baire class $n$ or less iff 
there is a function $g$ continuous on $S \times R \times \cdots \times R=S \times R^{n}$ with

$$
f(s)=\int_{R} \cdots \int_{R} g\left(s, x_{1}, x_{2}, \cdots, x_{n}\right) d x_{1} \cdots d x_{n} .
$$

Proof. It will suffice to consider the case $n=2$.

If $f$ can be written as (5), then $f(s)=\lim _{m \rightarrow \infty} \int_{-m}^{m} \int_{R} g\left(s, x_{1}, x_{2}\right) d x_{1} d x$ and $f$ is a pointwise limit of functions in Baire class $\leqq 1$.

Conversely, suppose that $f$ belongs to Baire class $\leqq 2, f(s)=$ $\lim f_{n}(s)$, a pointwise limit of functions $f_{n}$ in Baire class $\leqq 1$. As in Theorem 2, with $f_{1}=0$,

$$
f(s)=\int_{R} \sum\left(f_{n+1}(s)-f_{n}(s)\right) h_{n}(y) d y .
$$

The integrand is a uniformly convergent sequence of functions in Baire class 1 or 0 and so is itself in Baire class 1 or 0 . Consequently the integrand can be written as

$$
\int_{R} g(s, y, z) d z
$$

with $g$ continuous on $S \times R \times R$. This is by applying Theorem 2 to the integrand defined on $S \times R$, with $S$ of the theorem replaced by $S \times R$. Hence $f$ has the form (5).

The integral which occurs in (5) is the iterated improper Riemann integral; it is not, in general, absolutely convergent.

In [6, II, §111] the notion of, say, a ul function is defined: such a function is the monotone non-increasing limit of a sequence of l.s.c. functions (which are, of course, themselves the monotone nondecreasing limit of sequences of continuous functions). Using the monotone convergence theorem twice, as in Theorem 1, any such $f$ can be written in the form of (5) with the integral a Lebesgue integral. Similarly the other classes, lu, ulu, etc. can be so represented by iterated Lebesgue integrals.

What properties of Lebesgue measure and of the real line support these theorems? That is, for a measure space $(T, \mu)$, when can we find $h$ continuous on $S \times T$ and represent $f(s)$ by $\int_{T} h(s, t) d \mu$ in place of $\int_{-\infty}^{\infty} h(s, x) d x$ ? We are not asking for minimal hypotheses, although that is an interesting problem, but for reasonably general sufficient conditions.

For Theorem 1 the answer is straightforward.

THEOREM 4. Let $T$ be a locally compact metric space which is 
$\sigma$-compact but not compact, and let $\mu$ be a regular measure on $T$ with $\mu(T)$ infinite. A nonnegative function $f$ on $S$ is lower semicontinuous iff there is a nonnegative function $h$, continuous on $S \times T$, with $h(s, \cdot)$ integrable for each $s$, and

$$
f(s)=\int_{T} h(s, t) d \mu(t) .
$$

Proof. Suppose that (6) holds as described. The compact space $T$ is the union $T=\cup K_{n}$ of a increasing sequence of compact sets $K_{n}$. Then

$$
f_{n}(s)=\int_{K_{n}} h(s, t) d \mu(t)
$$

is continuous. The sequence $\left\{f_{n}\right\}$ converges monotonically to $f$ which is therefore l.s.c.

By the regularity of $\mu$ there is an open neighborhood $U_{n}$ of $K_{n}$ with $\mu\left(U_{n}\right) \leqq \mu\left(K_{n}\right)+1<\infty$. By the normality of $T$ there is a continuous function $g, 0 \leqq g \leqq 1$, with $g\left(K_{n}\right)=1$ and $g\left(U_{n}^{c}\right)=0$. For $c=\int_{T} g d \mu, \int_{T}(g / c) d \mu=1$, and $0 \leqq g(t) / c \leqq 1 / \mu\left(K_{n}\right) \rightarrow 0$ with $n$. Thus there are nonnegative continuous functions on $T$ of integral 1 but taking on values as small as desired. Consequently there is a sequence $\left\{h_{n}\right\}$ of continuous functions on $T$ satisfying $0 \leqq h_{n} \leqq$ $1 /(2 n+1) 2^{n}$ and $\int_{T} h_{n} d \mu=1$. Proceed as in Theorem 1 to complete the proof.

The analog of Theorem 2, and thus Theorem 3, is more interesting.

The first requirement is a satisfactory definition of a conditionally convergent integral. The type of integral obtained will be governed by the choice of a collection $\left\{K_{\alpha}\right\}$ of compact sets.

DeFinition. Let $T$ be a noncompact topological space, $\mu$ a regular measure on $T$, and $\left\{K_{\alpha}\right\}$ a given collection of compact sets with the $\operatorname{limit} \lim K_{\alpha}=T$, the limit taken with the direction of set inclusion. For a continuous function $g$ the (conditional $\left\{K_{\alpha}\right\}$-integral) of $g$ is defined as the generalized limit, if it exists, $\lim \int_{K_{\alpha}} g d \mu$ taken over the sets $\left\{K_{\alpha}\right\}$ directed by set inclusion.

EXAMPLE 1. The real line with Lebesgue measure.

(a) $\left\{K_{\alpha}\right\}=\{[a, b]\}$. The integral is the conditional improper Riemann integral.

(b) $\left\{K_{\alpha}\right\}=\{[-c, c], c>0\}$. The integral is the conditional Cauchy 
Principal Value.

(c) $\left\{K_{\alpha}\right\}$ all compact sets. The integral is the (unconditional) Lebesgue integral.

EXAMPLE 2. The plane with Lebesgue measure.

$\left\{K_{\alpha}\right\}=\{[a, b] \times[c, d]\}$. The integral is the improper double Riemann integral.

EXAmple 3. Let $T$ be the interval $(a, b)$, and let $\alpha$ be a monotone increasing real valued function on $T$ with $\alpha\left(\alpha^{+}\right)=0$ and $\alpha\left(b^{-}\right)=$ $+\infty$. Take $d \mu=d \alpha$. With $\left\{K_{\alpha}\right\}=\{[c, d]: a<c<d<b\}$ the integral is the improper Riemann-Stieltjes integral $\int_{a}^{b} g d \alpha$.

EXAMPLE 4. Let $T$ be the positive integers, $\mu$ counting measure, and $K_{n}=\{1,2, \cdots, n\}$. Then the $\left\{K_{n}\right\}$-integral is the series $\int g d \mu=$ $\sum g(i)$; in general a conditionally, not absolutely, converging series.

Any finite products of these examples will furnish additional examples.

The second requirement for a satisfactory generalization of Theorem 2 is the existence of functions on $T$ which behave essentially like the functions $\left\{h_{n}\right\}$ in the proof of Theorem 2. Theorem 5 will show that it is sufficient to have the following condition satisfied:

$\left(^{*}\right)$ Let $T$ and $\mu$ be given with $\mu(T)=\infty$, and let $\left\{K_{\alpha}\right\}$ be the collection of compact sets which are specified in order to define the conditional integral. The condition needed is that there be a sequence of compact sets $\left\{C_{n}\right\}$ increasing to $T$ with $\mu\left(K_{\alpha} \cap C_{n}\right) / \mu\left(C_{n}\right)$ converging monotonically (to zero) for each sufficiently large $K_{\alpha}\left(K_{\alpha} \geqq K_{\alpha_{0}}\right)$.

For the examples above: zero.

(1.a) $\left\{C_{n}\right\}=\{[-n, n]: n=1,2, \cdots\}, K_{\alpha_{0}}$ any interval containing

(1.b) As in (1.a).

(1.c) Theorem 5 shows that there is no collection $\left\{C_{n}\right\}$ satisfying (*); for if there were, then, as is discussed following Theorem 1, every Baire class 1 function would be a function of Hausdorff's type $d$.

2. $\left\{C_{n}\right\}=\{[-n, n] \times[-n, n]: n=1,2, \cdots\}, K_{\alpha_{0}}$ any rectangle containing the origin. This is a general result. If each member of a finite product satisfies $(*)$, then the product does also.

3. $\left\{C_{n}\right\}=\{[a+1 / n, b-1 / n]: n=1,2, \cdots\}, K_{\alpha_{0}}$ any interval containing zero.

4. $C_{n}=K_{n}$.

In general, if $\left\{K_{n}\right\}$ is a countable monotone family of compact 
sets, then $C_{n}=K_{n}$ will satisfy $\left({ }^{*}\right)$. Thus, by applying Theorem 5, one can represent each Baire class 0 or 1 function as in (7). Such a representation would not, in general, be possible using the Lebesgue intesgral, as we discussed following Theorem 1 .

There is a subtlety here: The smaller the family $\left\{K_{\alpha}\right\}$, the larger the class of continuous functions which are $\left\{K_{\alpha}\right\}$-integrable. One useful property of the improper Riemann integral is that the associated family $\left\{K_{\alpha}\right\}$ is large, and so while it integrates more continuous functions than the Lebesgue integral, still the functions which it integrates are not too badly behaved. Exactly how conflicting demands influence the "appropriate" choice of the family $\left\{K_{\alpha}\right\}$ is a deep matter, and our understanding of it shallow. We believe that when it is better understood, representation theorems in general settings, like Theorem 5, will be broadly used.

THEOREM 5. Let $T$ be a locally compact metric space which is $\sigma$-compact but not compact, and let $\mu$ be a regular measure on $T$ with $\mu(T)$ infinite. Further suppose that there is a sequence $\left\{C_{n}\right\}$ of compact sets increasing monotonically to $T$ with the property $\left(^{*}\right)$.

Then a function $f$ on $S$ belongs to Baire class 0 or 1 iff there is a continuous function $h$ on $S \times T$, with $h(s, \cdot)$ conditionally integrable (in the sense of the above definition) with

$$
f(s)=\int_{T} h(s, t) d \mu(t) .
$$

Proof. If $f$ can be represented in the form (7), then $f_{n}(s)=$ $\int_{C_{n}} h(s, t) d \mu(t)$ is a sequence of continuous functions converging to $f$. The function $f$ is therefore in Baire class 0 or 1 .

Conversely, suppose that $f$ belongs to Baire class 0 or 1 and is thus the pointwise $\operatorname{limit} f(s)=\lim f_{n}(s)$ of a sequence of continuous functions on $S$. As before, we may suppose that $\left|f_{n}\right| \leqq n$ and $f_{1}=0$. Set $g_{n}=\left(1 / \mu\left(C_{n}\right)\right) \chi_{c_{n}}$. Given $\delta>0$, by Lusin's theorem there is a continuous function $w_{n} \geqq 0$ of compact support with $\left|g_{n}-w_{n}\right| \leqq$ $2 / \mu\left(C_{n}\right)$, and $\int_{T}\left|w_{n}-g_{n}\right| d \mu \leqq \delta$. Let $a_{n}=\int w_{n} d \mu$. Then $1-\delta \leqq a_{n} \leqq$ $1+\delta$. By passing to a subsequence $\left\{h_{n}\right\}$ of $\left\{w_{n} / a_{n}\right\}$ and the corresponding subsequence of the $\left\{g_{n}\right\}$, which we will also call $\left\{g_{n}\right\}$, the following can be satisfied: $h_{n}$ continuous,

$$
0 \leqq h_{n} \leqq 1 /(2 n+1) 2^{n}, \quad \int_{T} h_{n} d \mu=1,
$$

and

$$
\int_{T}\left|h_{n}-g_{n}\right| d \mu \leqq 1 /(2 n+1) 2^{n}
$$


Define $h(s, t)=\sum\left(f_{n+1}(s)-f_{n}(s)\right) h_{n}(t)$, continuous on $S \times T$. Let $K$ be a set in $\left\{K_{\alpha}\right\}$ large enough that the condition $\left({ }^{*}\right)$ on the (sub)sequence $\left\{C_{n}\right\}$ is satisfied. Let $\Delta_{n} f(s)=f_{n+1}(s)-f_{n}(s)$. Given $\varepsilon>0$, choose $N$ so that $\left|\sum_{h=k}^{\infty} \Delta_{n} f(s)\right| \leqq \varepsilon$ for $k \geqq N$. Then

$$
\begin{aligned}
& \int_{K} h(s, t) d \mu(t)=\sum_{1}^{\infty} \Delta_{n} f(s) \int_{K} h_{n}(t) d \mu(t) \\
& \quad+\sum_{N+1}^{\infty} \Delta_{n} f(s) \int_{K}\left(h_{n}(t)-g_{n}(t) d \mu(t)+\sum_{N+1}^{\infty} \Delta_{n} f(s) \int_{K} g_{n}(t) d \mu(t) .\right.
\end{aligned}
$$

As in the proof of Theorem 2, the last term of (8) is bounded by $\varepsilon$. The second term is bounded by $\sum_{N+1}^{\infty}\left|\Delta_{n} f(s)\right| \int\left|g_{n}-h_{n}\right| \leqq 1 / 2^{N}$. Letting $K$ increase towards $T$, through members of $\left\{K_{\alpha}\right\}, \int_{K} h_{n}(t) d \mu(t) \rightarrow 1$, for $1 \leqq n \leqq N$, in the first term of (8). Hence $\lim \int_{K_{\alpha}} k_{k}(s, t) d \mu(t)=f(s)$.

\section{REFERENCES}

1. de la Vallée-Poussin, Integrales de Lebesgue, Fonctions d'ensemble, Classes de Baire, Gauthier-Villars, Paris, 1916.

2. W. F. Donoghue Jr., Distributions and Fourier Transforms, Academic Press, New York, 1969.

3. F. Hausdorff, Set Theory, Chelsea (translation of 1937 edition), New York, 1957.

4. T. Hawkins, Lebesgue's Theory of Integration: Its Origin and Development, University of Wisconsin Press, Madison, 1970.

5. E. Hewitt and K. Stromberg, Real and Abstract Analysis, Springer, New York, 1965.

6. E. W. Hobson, The Theory of Functions of a Real Variable, Volumes I and II, Cambridge University Press, Cambridge, 1927. (Reprinted by Dover in 1957).

7. H. L. Royden, Real Analysis, Macmillan, New York, 1963.

Received June 4, 1976.

UNIVERSITY OF CALIFORNIA-IRvine 


\section{PACIFIC JOURNAL OF MATHEMATICS}

\section{EDITORS}

RICHARD ARENS (Managing Editor)

University of California

Los Angeles, California 90024

\section{J. DugunduI}

Department of Mathematics University of Southern California Los Angeles, California 90007

D. Gilbarg and J. Milgram

Stanford University

Stanford, California 94305

\author{
R. A. Beaumont \\ University of Washington \\ Seattle, Washington 98105
}

\section{ASSOCIATE EDITORS}
B. H. NeUmanN
F. WOLF
K. YosHIDA

\section{SUPPORTING INSTITUTIONS}

\author{
UNIVERSITY OF BRITISH COLUMBIA \\ CALIFORNIA INSTITUTE OF TECHNOLOGY \\ UNIVERSITY OF CALIFORNIA \\ MONTANA STATE UNIVERSITY \\ UNIVERSITY OF NEVADA \\ NEW MEXICO STATE UNIVERSITY \\ OREGON STATE UNIVERSITY \\ UNIVERSITY OF OREGON \\ OSAKA UNIVERSITY
}

\author{
UNIVERSITY OF SOUTHERN CALIFORNIA \\ STANFORD UNIVERSITY \\ UNIVERSITY OF HAWAII \\ UNIVERSITY OF TOKYO \\ UNIVERSITY OF UTAH \\ WASHINGTON STATE UNIVERSITY \\ UNIVERSITY OF WASHINGTON \\ AMERICAN MATHEMATICAL SOCIETY
}

The Supporting Institutions listed above contribute to the cost of publication of this Journal, but they are not owners or publishers and have no responsibility for its content or policies.

Mathematical papers intended for publication in the Pacific Journal of Mathematics should be in typed form or offset-reproduced, (not dittoed), double spaced with large margins. Please do not use built up fractions in the text of your manuscript. You may however, use them in the displayed equations. Underline Greek letters in red, German in green, and script in blue. The first paragraph or two must be capable of being used separately as a synopsis of the entire paper. Items of the bibliography should not be cited there unless absolutely necessary, in which case they must be identified by author and Journal, rather than by item number. Manuscripts, in triplicate, may be sent to any one of the editors. Please classify according to the scheme of Math. Reviews, Index to Vol. 39. All other communications should be addressed to the managing editor, or Elaine Barth, University of California, Los Angeles, California, 90024.

The Pacific Journal of Mathematics expects the author's institution to pay page charges, and reserves the right to delay publication for nonpayment of charges in case of financial emergency.

100 reprints are provided free for each article, only if page charges have been substantially paid. Additional copies may be obtained at cost in multiples of 50 .

The Pacific Journal of Mathematics is issued monthly as of January 1966. Regular subscription rate: $\$ 72.00$ a year (6 Vols., 12 issues). Special rate: $\$ 36.00$ a year to individual members of supporting institutions.

Subscriptions, orders for back numbers, and changes of address should be sent to Pacific Journal of Mathematics, 103 Highland Boulevard, Berkeley, California, 94708.

PUBLISHED BY PACIFIC JOURNAL OF MATHEMATICS, A NON-PROFIT CORPORATION

Printed at Kokusai Bunken Insatsusha (International Academic Printing Co., Ltd.), 8-8, 3-chome, Takadanobaba, Shinjuku-ku, Tokyo 160, Japan. 


\section{Pacific Journal of Mathematics}

Patricia Andresen and Marvin David Marcus, Weyl's inequality and

quadratic forms on the Grassmannian .......................

George Bachman and Alan Sultan, Regular lattice measures: mappings and

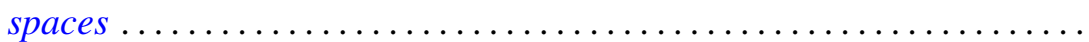

David Geoffrey Cantor, On certain algebraic integers and approximation by rational functions with integral coefficients ...................

James Richard Choike, On the value distribution of functions meromorphic in the unit disk with a spiral asymptotic value ..................

David Earl Dobbs, Divided rings and going-down................ 353

Mark Finkelstein and Robert James Whitley, Integrals of continuous

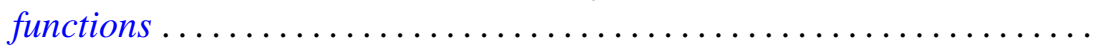

Ronald Owen Fulp and Joe Alton Marlin, Integrals of foliations on manifolds with a generalized symplectic structure ...............

Cheong Seng Hoo, Principal and induced fibrations .................

Wu-Chung Hsiang and Richard W. Sharpe, Parametrized surgery and

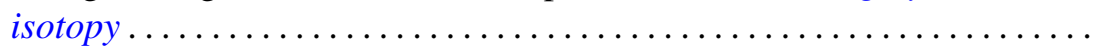

Surender Kumar Jain, Surjeet Singh and Robin Gregory Symonds, Rings whose proper cyclic modules are quasi-injective .................

Pushpa Juneja, On extreme points of the joint numerical range of commuting normal operators...

Athanassios G. Kartsatos, Nth order oscillations with middle terms of order $N-2$.

John Keith Luedeman, The generalized translational hull of a

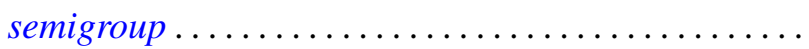

Louis Jackson Ratliff, Jr., The altitude formula and DVR's ...

Ralph Gordon Stanton, C. Sudler and Hugh C. Williams, An upper bound for the period of the simple continued fraction for $\sqrt{D}$...

David Westreich, Global analysis and periodic solutions of second order systems of nonlinear differential equations...

David Lee Armacost, Correction to: "Compactly cogenerated LCA

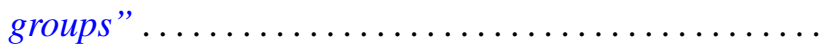

Jerry Malzan, Corrections to: "On groups with a single involution" .

David Westreich, Correction to: "Bifurcation of operator equations with unbounded linearized part" ...................... 